\title{
Preparation and Characterization of Multifunctional Chitin/Lignin Materials
}

\author{
Lukasz Klapiszewski, ${ }^{1}$ Marcin Wysokowski, ${ }^{1}$ \\ Izabela Majchrzak, ${ }^{1}$ Tomasz Szatkowski, ${ }^{1}$ Magdalena Nowacka, ${ }^{1}$ \\ Katarzyna Siwińska-Stefańska, ${ }^{1}$ Karolina Szwarc-Rzepka, ${ }^{1}$ Przemysław Bartczak, ${ }^{1}$ \\ Hermann Ehrlich, ${ }^{2}$ and Teofil Jesionowski ${ }^{1}$ \\ ${ }^{1}$ Institute of Chemical Technology and Engineering, Faculty of Chemical Technology, Poznan University of Technology, \\ M. Sklodowskiej-Curie 2, 60965 Poznan, Poland \\ ${ }^{2}$ Institute of Experimental Physics, Faculty of Chemistry and Physics, TU Bergakademie Freiberg, 09599 Freiberg, Germany \\ Correspondence should be addressed to Teofil Jesionowski; teofil.jesionowski@put.poznan.pl
}

Received 16 July 2013; Revised 16 August 2013; Accepted 17 August 2013

Academic Editor: Yuan Zhang

Copyright (C) 2013 Łukasz Klapiszewski et al. This is an open access article distributed under the Creative Commons Attribution License, which permits unrestricted use, distribution, and reproduction in any medium, provided the original work is properly cited.

\begin{abstract}
Multifunctional chitin/lignin materials were synthesized. In order to combine mechanical milling of the biopolymers with simultaneous mixing, a centrifugal ball mill was utilized. The resulting materials, differing in terms of the proportions of precursors used, underwent detailed physicochemical and dispersive-morphological analysis. On the basis of FT-IR spectra and results of elemental analysis, the efficiency of the preparation of the materials was determined. The influence of the precursors on the thermal stability of the resulting systems was also evaluated. Zeta potential was determined as a function of $\mathrm{pH}$ to describe the electrokinetic stability of aqueous dispersions. This is important for evaluating the utility of the materials and indirectly confirms the effectiveness of the proposed method of synthesis of chitin/lignin products. Measurements were performed to determine basic colorimetric parameters, crucial in the production technology of multiple colored materials. It is expected that chitin/lignin materials will find a wide range of applications (biosorbents, polymer fillers, and electrochemical sensors), as they combine the unique properties of chitin with the specific structural features of lignin to provide a multifunctional material.
\end{abstract}

\section{Introduction}

Lignin is an organic substance found in wood and the lignified elements of plants, such as straw. From a chemical point of view, the parent lignin is an amorphous, polyphenolic material arising from enzyme-mediated dehydrogenative polymerization of three phenylpropanoid monomers: $\mathrm{p}$ coumaryl, coniferyl, and sinapyl alcohols [1-4]. The copolymer thus formed consists of substituted C 9 units ( 6 aromatic and 3 propene carbons) interconnected by $\mathrm{C}-\mathrm{O}$ (mostly etheric) or C-C bonds [5].

Lignin from various pulping processes has been shown to be applicable in electrochemical sensors owing to its residual quinone moieties, which are redox and thus electroactive $[6,7]$. In order to intensify the chemical properties of lignin that make it suitable for electrochemical applications, various methods of combining these materials with electrical conductors (carbon nanotubes or conducting polymers) have been proposed $[8,9]$. Lignin has been also studied as a potential low-cost "green" biosorbent of heavy metals [1012]. The usefulness of lignin in the adsorption of harmful organic compounds (including heavy metals) results from the presence of multiple functional groups in its structure, including phenolic, hydroxyl, carboxyl, and methoxy groups. In addition to the sorption of metals, lignin is also used for the removal of other compounds, such as dyes, pesticides, and phenols [13]. Lignin can also serve as an additive to synthetic polymers, giving them distinctive and unique properties [14, 15].

Numbers of scientific reports prove that chitin is one of the key polymers of the 21 st century $[16,17]$. Chitin is a building block of the skeletons of crustaceans $[18,19]$, insects 


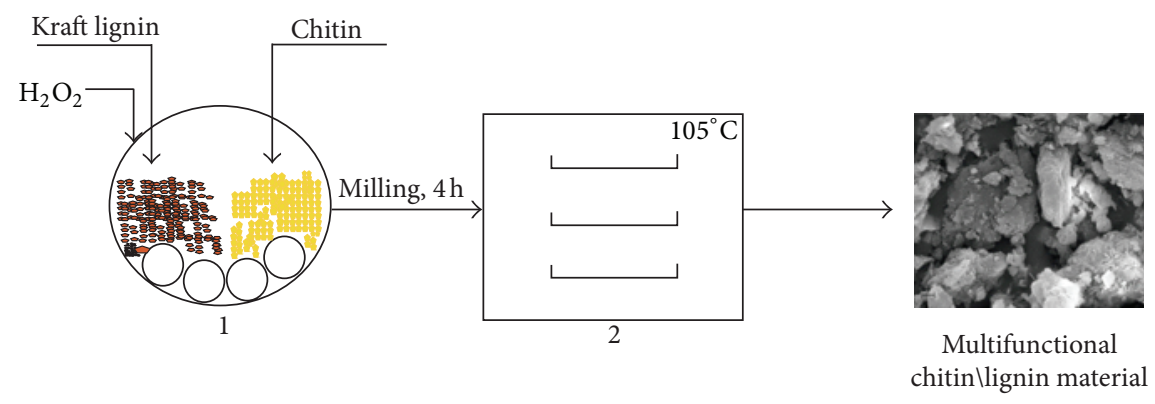

FIGURE 1: Scheme of chitin/lignin material preparation: (1) ball mill and (2) stationary drier.

[20], and diatoms [21]. Recently the biopolymer has been discovered in the skeletons of several species of marine sponges [22-24]. From a chemical point of view chitin is a linear aminopolysaccharide, composed of $N$-acetylglucosamine units linked by $\beta$-1,4-glycosidic bonds [25]. The unique properties of chitin are due to the presence of (acetyl)amino groups in the polysaccharide backbone [26]. For instance, biodegradability, nontoxicity, and bioactivity contribute to applications of chitin in various areas of biomedicine [27-30]. On the other hand, its high affinity to peptides and metal complexation is interesting from the point of view of catalysis [31] and of waste water treatment $[32,33]$. The presence of reactive $-\mathrm{OH}$ and $-\mathrm{NH}$ groups in chitin's structure also provides opportunities for its functionalization [34]. This property enables the obtaining of novel, advanced chitin-based materials with a wide spectrum of application, including polymer fillers, adsorbents, biosensors [35], a drug delivery systems.

Consequently, in this study, chitin powder was modified with Kraft lignin solution to obtain multifunctional chitin/lignin materials. Combination of these two polymers has been poorly studied in the literature. However, Wang and Xing [36] proved that modification of chitin with lignin leads to improvement in the adsorption of hydrophobic organic compounds. In this study a synthesis of advanced materials was performed by a mechanochemical method. This method was chosen because it can promote reactions between solids quickly and quantitatively, with either no added solvent or only nominal amounts. Additionally, it is highly efficient with regard to the use of energy, time, and materials [37]. In comparison with the method described by Wang and Xing [36], the main advantage of the proposed mechanochemical method is the elimination of the need to use organic solvent (acetone), which makes the process environmentally friendly.

\section{Experimental Section}

2.1. Materials. Chitin powder from crab shells was mechanically combined with Kraft lignin (both biopolymers were purchased from Sigma-Aldrich). The final chitin/lignin products were obtained using various proportions of the reagents, which were additionally treated with $15 \%$ hydrogen peroxide (Chempur).

2.2. Preparation of Multifunctional Chitin/Lignin Materials. Chitin and lignin were combined using a process of mechanical milling of the materials with simultaneous homogenization, using a centrifugal ball mill (Fritsch). The substrates were soaked in a small amount of $15 \%$ hydrogen peroxide and were closed in a milling container together with the milling balls. The container with the precursors was then fitted to the mill's metal base. Milling took place with simultaneous movement of the metal base and container. The rotational speed of the rotating milling container was $300 \mathrm{rpm}$. In order to achieve the required homogeneity of the final material, milling was carried out for 4 hours. The product was then placed in a stationary drier at a high temperature of $105^{\circ} \mathrm{C}$ for 12 hours. A simplified process scheme of the preparation of chitin/lignin products is shown in Figure 1.

Immediately after the drying process, the chitin/lignin materials were passed through a sieve with size equal $100 \mu \mathrm{m}$, thus increasing their uniformity. Products with varying content of chitin in proportion to lignin were obtained. In the further part of the research, the products were subjected to physicochemical analysis.

\subsection{Evaluation of Physicochemical Properties}

2.3.1. Scanning Electron Microscopy. The morphology and microstructure of the chitin/lignin products were analyzed to obtain detailed information concerning such properties as dispersion, morphology of the grains, structure of individual particles, and agglomeration characteristics. The observations were based on SEM images recorded from a EVO40 scanning electron microscope (Zeiss). Prior to testing, the samples were coated with Au for a time of 15 seconds, using a Balzers PV205P coater.

2.3.2. FT-IR Analysis. The chitin/lignin materials and precursors (chitin and Kraft lignin) were also subjected to FT-IR spectral analysis, using an IFS $66 \mathrm{v} / \mathrm{S}$ instrument (Bruker). Here the materials were analyzed in tablet form made by pressing a mixture of anhydrous $\mathrm{KBr}$ (ca. $0.1 \mathrm{~g}$ ) and $1 \mathrm{mg}$ of the tested substance in a special steel ring, under a pressure of approximately $10 \mathrm{MPa}$. The transparent tablet was placed in a cuvette, which was then fitted in the clamp of the apparatus, at the focal point of the light beam. Analysis was performed over a wave number range of 4000 to $400 \mathrm{~cm}^{-1}$ (at a resolution of $\left.0.5 \mathrm{~cm}^{-1}\right)$. 
2.3.3. Elemental Analysis. The elemental contents of the products were established using a Vario EL Cube instrument (Elementar Analysensysteme $\mathrm{GmbH}$ ), which is capable of registering the percentage content of carbon, hydrogen, nitrogen, and sulfur within samples, after high-temperature combustion. A properly weighed sample was placed on an 80 -position autosampler and combusted. The decomposed sample was carried in a stream of helium gas into a chromatography column, where the percentage of each element was analyzed.

2.3.4. Electrokinetic Characteristics. The zeta potential was measured with a Zetasizer Nano ZS equipped with an autotitrator. The measurements were performed in a $0.001 \mathrm{M}$ solution of $\mathrm{NaCl}$. This instrument employs a combination of electrophoresis and laser measurement of particle mobility, based on the Doppler phenomenon. The speed of particles moving in the liquid in an electric field, known as the electrophoretic mobility, is measured. Then from the Henry equation (1), the value of the zeta potential is obtained:

$$
\mu_{E}=\frac{2 \varepsilon \zeta f(\kappa a)}{3 \eta},
$$

where $\mu_{E}$ denotes electrophoretic mobility, $\varepsilon$ denotes the dielectric constant, $\zeta$ denotes the electrokinetic (zeta) potential, $\eta$ denotes the viscosity, and $f(\kappa a)$ denotes the Henry function.

The Henry function $f(\kappa a)$ is monotonic, increasing from 1.0 at $\kappa a=0$ to 1.5 at $\kappa a=\infty$. At the lower limit, it reduces to the Hückel equation $\left(\mu_{E}=2 \varepsilon \zeta / 3 \eta\right)$, and at the upper limit, it reduces to the Smoluchowski equation $\left(\mu_{E}=\varepsilon \zeta / \eta\right)$.

2.3.5. Thermal Stability. A thermogravimetric analyzer (TG/ DTA/DSC, model Jupiter STA 449F3, Netzsch) was used to investigate the thermal decomposition behavior of the samples. Measurements were carried out under flowing nitrogen $\left(10 \mathrm{~cm}^{3} / \mathrm{min}\right)$ at a heating rate of $10^{\circ} \mathrm{C} / \mathrm{min}$ over a temperature range of $25-1000^{\circ} \mathrm{C}$, with an initial sample weight of approximately $5 \mathrm{mg}$.

2.3.6. Porous Structure Analysis. In order to characterize the parameters of the porous structure of the examined substances, nitrogen adsorption/desorption isotherms at $77 \mathrm{~K}$, surface area, pore volume, and average pore size were determined using an ASAP 2020 (Accelerated Surface Area and Porosimetry) instrument (Micromeritics Instrument Co.). All samples were degassed at $120^{\circ} \mathrm{C}$ for 4 hours in a vacuum chamber prior to measurement. The specific surface area was determined by the multipoint BET method using adsorption data under relative pressure $\left(p / p_{0}\right)$. The BJH (Barrett-JoynerHalenda) method was applied to determine the total pore volume and the average pore size.

2.3.7. Adsorption Experiments. Adsorption tests were performed with the use of tetrahydrate cadmium nitrate as a precursor of cadmium(II) ions (POCh SA). In order to determine the optimum time of heavy metal removal from aqueous solutions, the adsorption process was carried out over $30,60,90,120$, and 180 minutes, with the cadmium(II) ion concentration equal to $30 \mathrm{mg} / \mathrm{dm}^{3}$. Time optimization was performed for three sorbent types independently: pure lignin, chitin, and the final chitin/lignin material in a weight ratio of $1: 1$. The prepared cadmium(II) solutions were placed in a conical flask, into which $5.0 \mathrm{~g}$ of sorbent was added. The system was stirred using a magnetic stirrer (Ika Werke Labortechnik $\mathrm{GmbH}$ ) for the set length of time. After stirring, the mixture was filtered under reduced pressure, with the use of special apparatus and filters (Sartorius). The resulting precipitate was dried for 2 hours at $105^{\circ} \mathrm{C}$. The filtrate was then analyzed to determine the efficiency of adsorption.

2.3.8. Evaluation of Adsorption Efficiency. An important goal was to determine the effectiveness of removal of cadmium(II) ions from aqueous solution. For this purpose, atomic absorption spectrometry was used, which enables the detection of ions in the filtrate after the adsorption process. The analysis was performed on a Z-8200 spectrometer (Hitachi). Before the analysis, it was necessary to prepare a calibration curve. The results of the AAS analysis were used in calculations to determine the efficiency of cadmium(II) ion removal. For this purpose, the following equation was used:

$$
\% \text { removal }=\left(\frac{c_{0}-c_{e}}{c_{0}}\right) \times 100 \%,
$$

where $c_{0}$ and $c_{e}$ are, respectively, the initial and equilibrium concentrations of cadmium(II) ions (expressed in $\mathrm{mg} / \mathrm{dm}^{3}$ ).

2.3.9. Colorimetric Analysis. Colorimetric analysis was performed using a colorimeter (Specbos 4000, JETI Technische Instrumente $\mathrm{GmbH}$ ). Daylight (D65) was used as a standard light source. The instrument evaluated the color in terms of the CIE $L^{*} a^{*} b^{*}$ color space system. This describes all the colors visible to human eye and was created to serve as a device-independent model, extremely useful for the preparation of a reference sample. In this color space, $L^{*}$ represents the brightness, and $a^{*}$ and $b^{*}$ are appropriate color coordinates. The parameter $d E$ describes the total color change.

\section{Results and Discussion}

3.1. Dispersive-Morphological Properties. In order to evaluate the morphology and microstructures of the biopolymers, SEM photographs were taken (Figure 2). In the pictures shown it is easily observable how the precursors differ from each other. Chitin (Figure 2(a)) is characterized by nonhomogeneity and the presence of irregular fragments in its structure. Lignin possesses irregularly shaped particles as well, but its structure is slightly more homogeneous (Figure 2(b)).

SEM photographs were taken for selected products (Figure 3). It is easily noticeable that the ratio of the biopolymers used to make the samples significantly influences their morphological and microstructural properties. The character of a given sample clearly depends on the quantities of precursors used. 


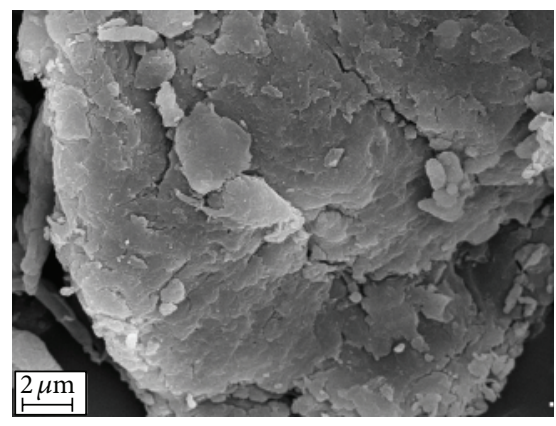

(a)

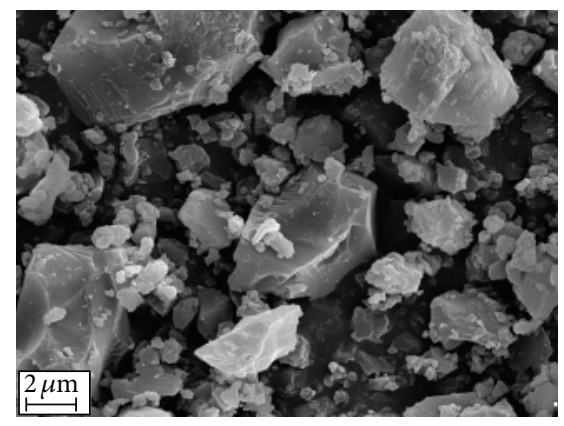

(b)

FigurE 2: SEM images of chitin powder from crab shells (a) and Kraft lignin (b).

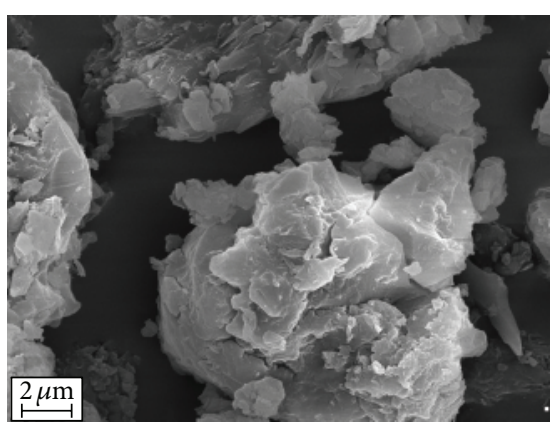

(a)

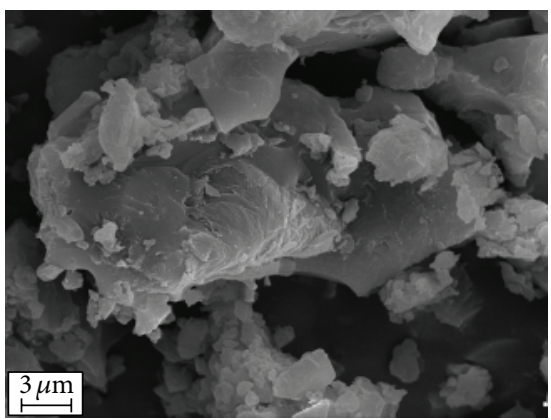

(d)

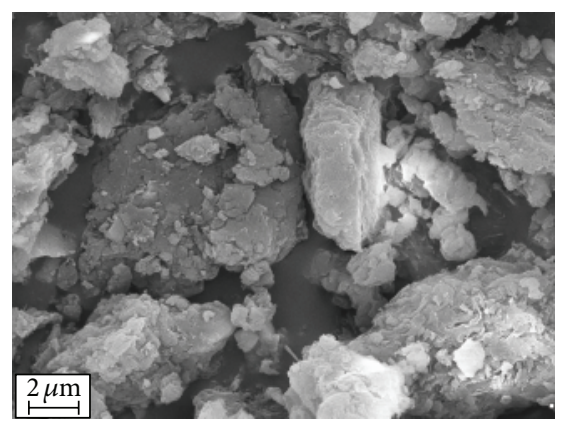

(b)

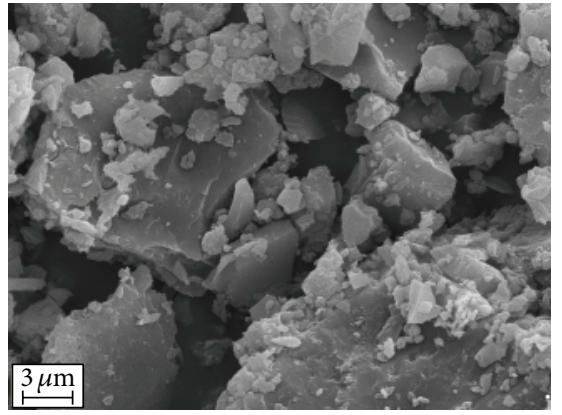

(e)

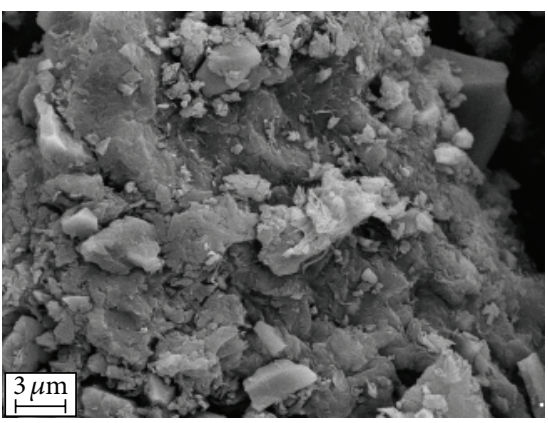

(c)

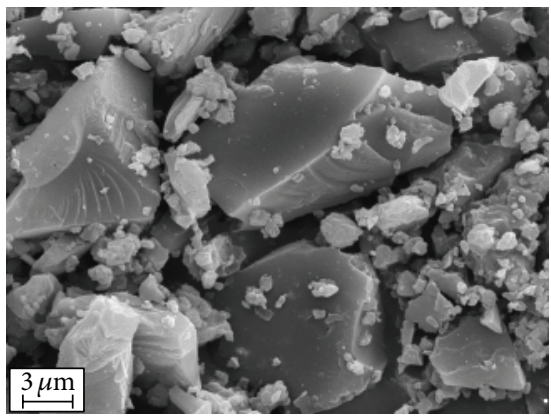

(f)

Figure 3: SEM images of chitin/lignin material samples: 1 (a), 4 (b), 7 (c), 8 (d), 10 (e), and 13 (f).

3.2. FT-IR Analysis. Analysis of the FT-IR spectra were carried out to confirm the presence of characteristic functional groups in the tested compounds, through measurement of the absorption intensity of specific infrared radiation. Additionally, based on the adsorption band, conclusions can be drawn regarding the appropriateness and effectiveness of the proposed methodology of multifunctional chitin/lignin material synthesis. Figure 4 shows the FT-IR spectra of the precursors, lignin and chitin, and final chitin/lignin materials obtained by the proposed method.

In analysis of the lignin spectrum, the following bands were detected: stretching vibrations of $\mathrm{O}-\mathrm{H}$ groups (phenolic $-\mathrm{OH}$ and aliphatic $-\mathrm{OH}$ ) in the range $3600-3200 \mathrm{~cm}^{-1}$ and C-H stretching vibrations in the range $2960-2920 \mathrm{~cm}^{-1}\left(\mathrm{CH}_{3}\right.$ and $\left.\mathrm{CH}_{2}\right)$ and $2850-2840 \mathrm{~cm}^{-1}\left(\mathrm{OCH}_{3}\right)$. A wider band in the range $1710-1550 \mathrm{~cm}^{-1}$ results from stretching vibrations of $\mathrm{C}=\mathrm{O}$ bonds. Also of significance in the analysis of the lignin FT-IR spectrum are bands with absorption maxima at the wave numbers $1375 \mathrm{~cm}^{-1}, 1265 \mathrm{~cm}^{-1}$, and $1220 \mathrm{~cm}^{-1}$, associated with stretching vibrations of $\mathrm{C}-\mathrm{O}, \mathrm{C}-\mathrm{O}(\mathrm{H})$, and $\mathrm{C}-\mathrm{O}(\mathrm{Ar})$ bonds of phenolic groups, as well as etheric bonds, which play an important role in the connection of elements in the analyzed biopolymer. The presence of $\mathrm{C}-\mathrm{O}-\mathrm{C}$ etheric bonds is additionally confirmed by a stretching vibration band at wave number $1045 \mathrm{~cm}^{-1}$. The last noteworthy group of bands in the case of lignin consists of in-plane deformation bands $\delta_{\mathrm{ip}} \mathrm{Ar} \mathrm{C}-\mathrm{H}\left(1140 \mathrm{~cm}^{-1}\right)$ and out-of-plane $\delta_{\mathrm{op}} \mathrm{Ar} \mathrm{C}-$ $\mathrm{H}$ (bands at wave numbers below $1000 \mathrm{~cm}^{-1}$, including $854 \mathrm{~cm}^{-1}, 816 \mathrm{~cm}^{-1}$, and $790 \mathrm{~cm}^{-1}$ ). The analysis of Kraft lignin performed for the purpose of this work is in agreement with the data presented in previously published papers [38, 39]. 

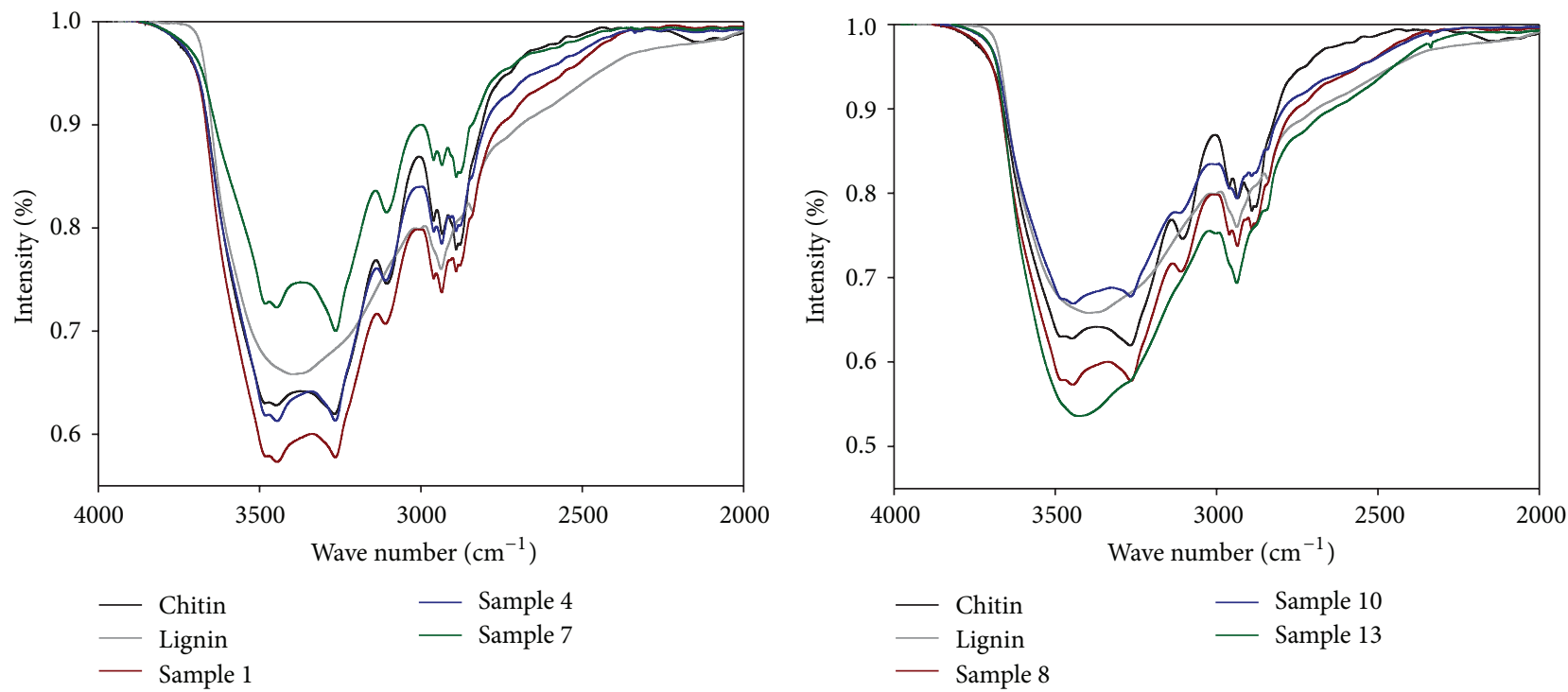

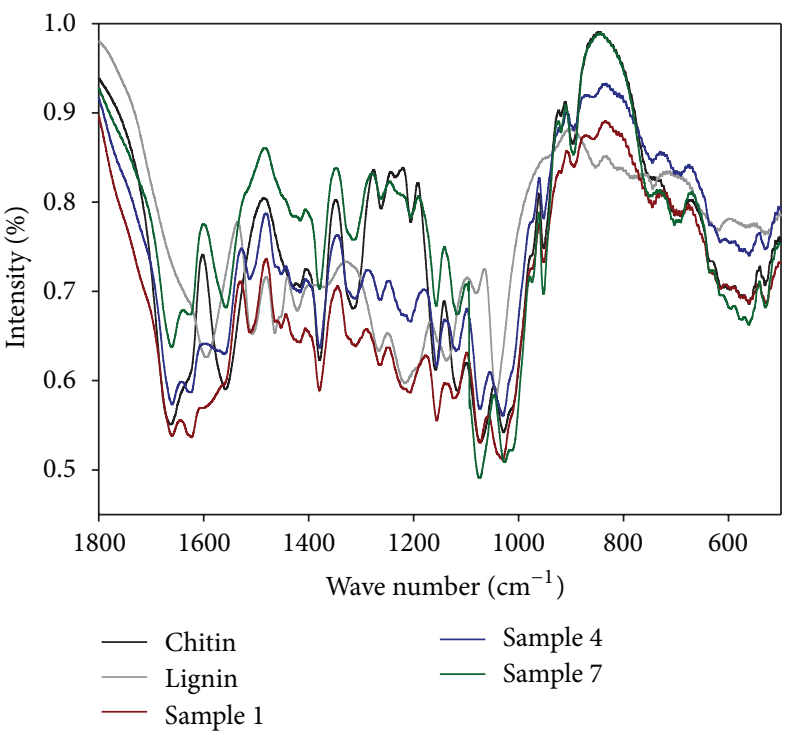

(a)

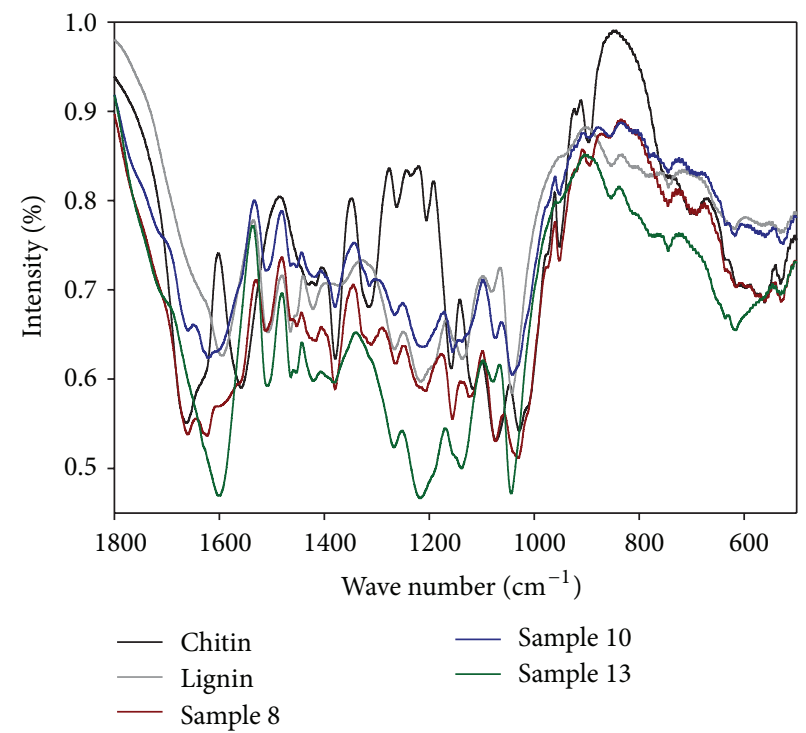

(b)

FIGURE 4: FT-IR spectra of the precursors and of selected chitin/lignin materials: samples 1, 4, and 7 (a) and 8, 10, and 12 (b).

In turn, the analysis of chitin revealed the presence of bands corresponding to stretching vibrations of $\mathrm{O}-\mathrm{H}$ groups in the range $3600-3400 \mathrm{~cm}^{-1}$, asymmetric stretching vibrations at wave number $3268 \mathrm{~cm}^{-1}$, and symmetric vibrations at $3106 \mathrm{~cm}^{-1}$ originating from $\mathrm{N}-\mathrm{H}$ groups. A stretching vibration band in the range $3000-2800 \mathrm{~cm}^{-1}$ is associated with the presence of $\left(\mathrm{CH}_{3}+\mathrm{CH}_{2}\right)$ groups. A wider band corresponding to stretching vibrations in the range 1660$1620 \mathrm{~cm}^{-1}$ is the so-called first amide band characteristic of chitin, which results from the overlapping of stretching vibration bands of $\mathrm{C}=\mathrm{O}$ groups. The second amide band is visible in the chitin spectrum at a wave number of $1558 \mathrm{~cm}^{-1}$. This band is undoubtedly associated with stretching vibrations of $\mathrm{C}-\mathrm{N}$ groups and bending vibrations of $\mathrm{N}-\mathrm{H}$. The region in range $1420-1375 \mathrm{~cm}^{-1}$ is attributed to bending vibrations associated with $-\mathrm{CH}_{2}$ and $\mathrm{C}-\mathrm{CH}_{3}$ groups. A weak absorption band of stretching and bending vibrations at wave number $1312 \mathrm{~cm}^{-1}$ (the third amide band) is associated with $\mathrm{C}-\mathrm{N}$ and $\mathrm{N}-\mathrm{H}$ groups, respectively. A wide band in the range 1250 $950 \mathrm{~cm}^{-1}$ is attributed to asymmetric stretching vibrations of $\mathrm{C}-\mathrm{O}-\mathrm{C}$ groups and stretching vibrations of $\mathrm{C}-\mathrm{O}$ groups. Of importance in the chitin spectrum is a weak band in the range $896-890 \mathrm{~cm}^{-1}$, which confirms the presence of the $\beta$ 1,4 -glycoside bond in the biopolymer structure. The analysis carried out for chitin is in agreement with available literature data concerning $\alpha$-chitin [40-42].

In Figures 4(a) and 4(b), FT-IR spectra for selected chitin/lignin materials are presented. Analysis of the spectra indicates that the process of chitin/lignin product synthesis was fully controlled and completed with satisfactory results. 

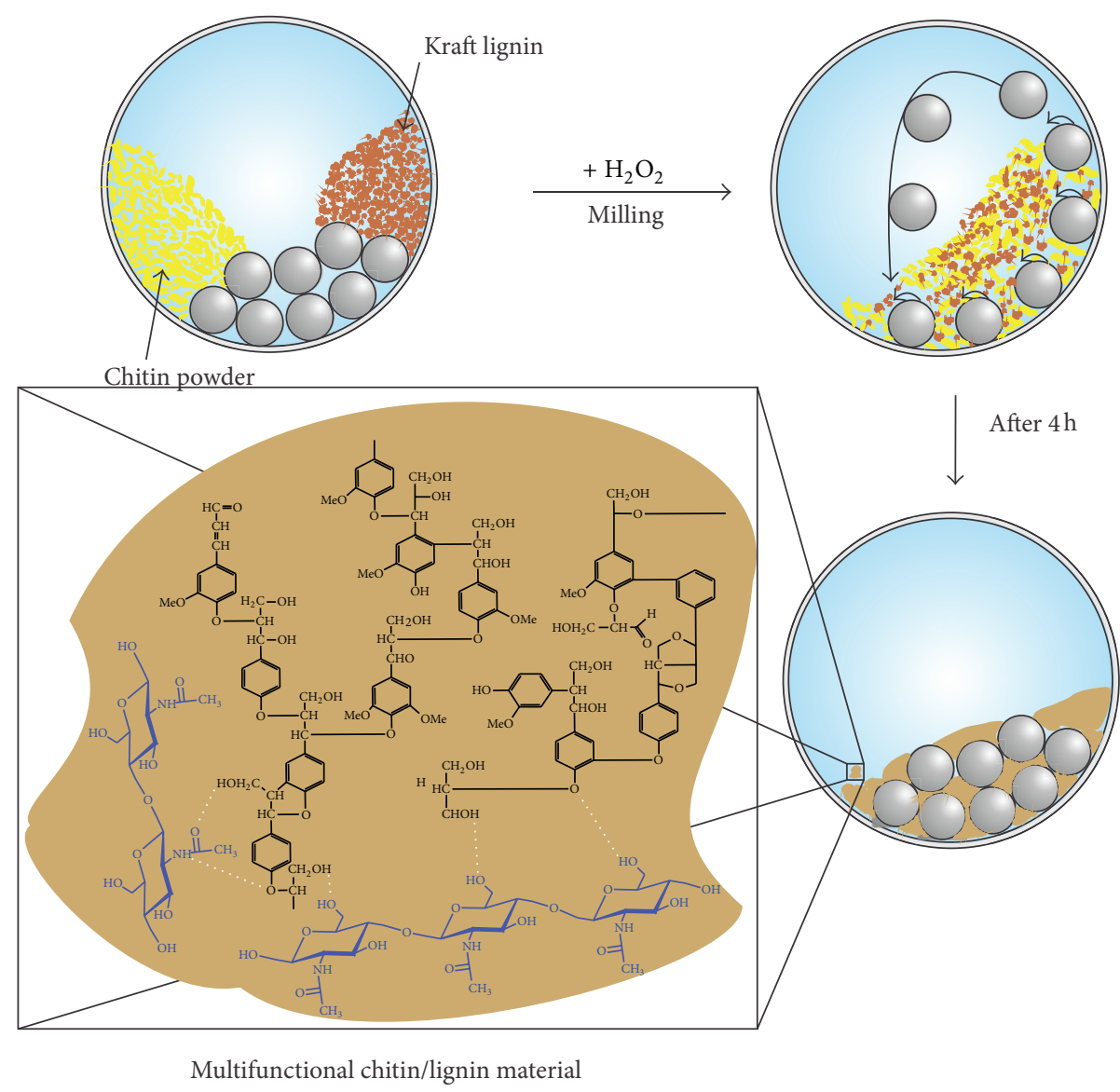

Figure 5: Schematic representation of possible interactions in the obtained chitin/lignin materials.

Individual bands characteristic of the discussed precursors overlap with bands obtained for the final products. Additionally, modification of the mass fraction of any of the precursors causes changes in the peaks' intensity. For instance, when the mass fraction of lignin decreases in products 1 to 7 , the intensity of the bands in the spectrum also decreases. The results obtained at this stage of the investigation confirmed the effectiveness of chitin/lignin preparation. An interesting relationship was observed for product 13 (with a chitin : lignin weight ratio of $0.05: 1$ ). The spectrum of this product is similar to the spectrum of pure lignin. This observation is obviously justified and additionally confirms the correctness of the suggested research methodology. The spectra reveal shifts and deformations of the first and second amide bands, which are probably the results of hydrogen bond formation between chitin and lignin. At this stage of the research a simplified mechanism of chitin and lignin combination was constructed (Figure 5). The proposed mechanism is based on the formation of hydrogen bonds between - $\mathrm{OH}$ groups of lignin and functional $\mathrm{C}=\mathrm{O},-\mathrm{OH}$, and $\mathrm{NH}$ groups of chitin.

3.3. Elemental Analysis. Elemental analysis, determining the percentage content of nitrogen, carbon, hydrogen, and sulfur, was performed for selected final products and for their synthesis precursors. The results are given in Table 1.
TABLE 1: Elemental content of nitrogen, carbon, hydrogen, and sulfur in the precursors and in chitin/lignin materials.

\begin{tabular}{lcccc}
\hline \multirow{2}{*}{ Sample number } & \multicolumn{4}{c}{ Elemental content (\%) } \\
& $\mathrm{N}$ & $\mathrm{C}$ & $\mathrm{H}$ & $\mathrm{S}$ \\
\hline Pure chitin & 6.21 & 40.54 & 7.36 & - \\
Pure lignin & - & 42.21 & 5.02 & 3.14 \\
\hline 1 & 6.06 & 45.25 & 8.26 & 3.13 \\
2 & 6.04 & 44.60 & 8.18 & 2.23 \\
3 & 5.99 & 44.44 & 8.14 & 1.11 \\
4 & 6.06 & 44.32 & 8.11 & 0.85 \\
5 & 6.17 & 43.01 & 8.04 & 0.51 \\
6 & 6.04 & 42.80 & 8.04 & 0.30 \\
7 & 6.12 & 42.82 & 8.03 & 0.05 \\
8 & 4.32 & 43.54 & 7.34 & 3.11 \\
9 & 2.34 & 44.51 & 6.61 & 3.10 \\
10 & 1.67 & 44.45 & 6.54 & 3.10 \\
11 & 1.19 & 44.19 & 6.11 & 3.06 \\
12 & 0.87 & 44.14 & 6.05 & 3.11 \\
13 & 0.38 & 43.93 & 5.85 & 3.14 \\
\hline
\end{tabular}

In analysis of the results obtained for the elemental composition of selected chitin/lignin materials, the quantities 


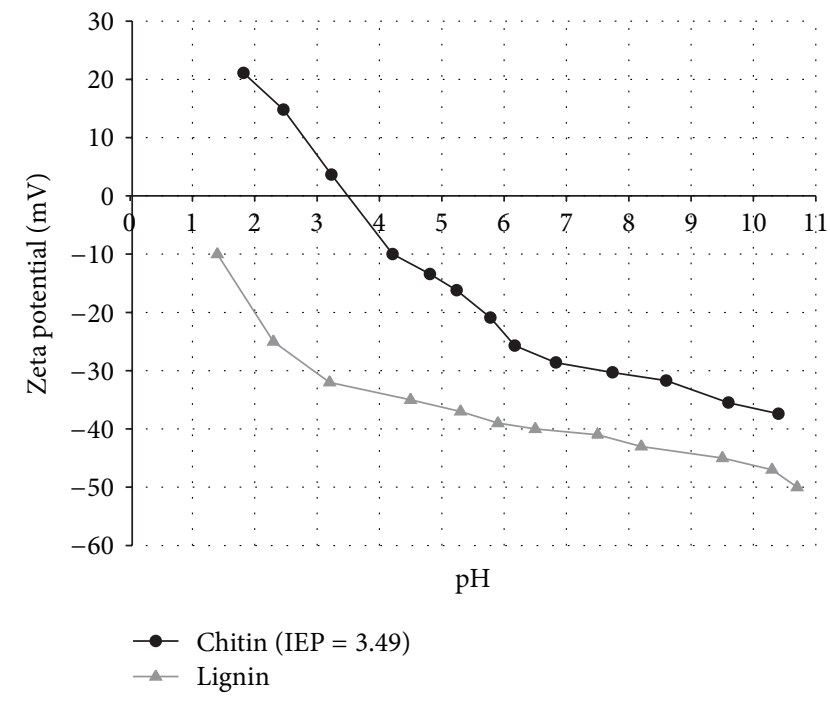

(a)

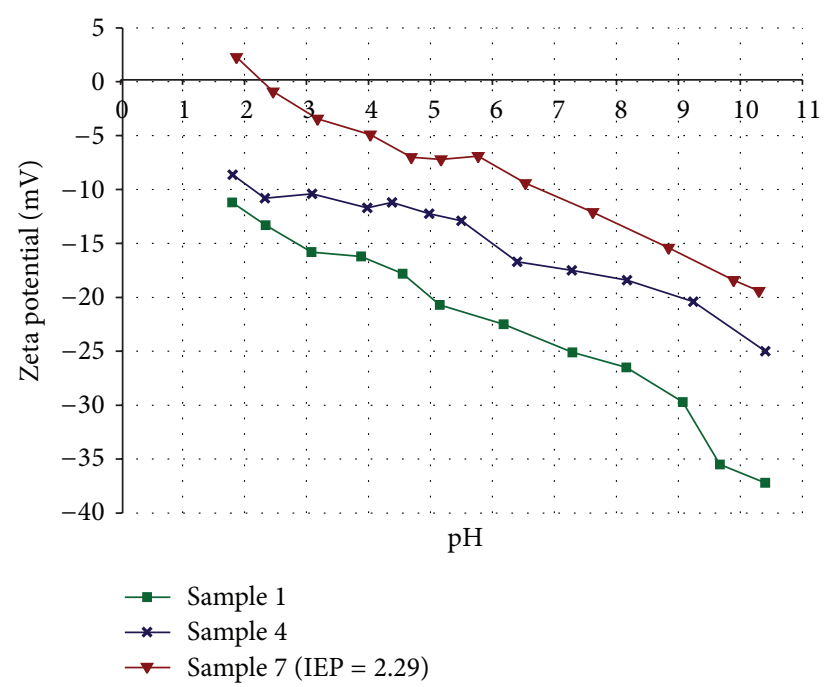

(b)

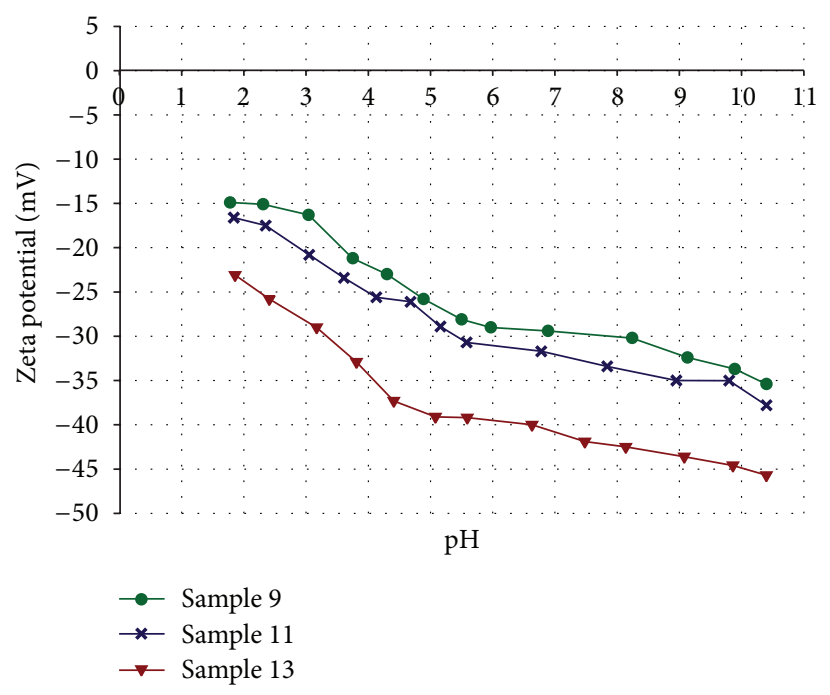

(c)

Figure 6: Zeta potential versus $\mathrm{pH}$ of precursors (a) and chitin/lignin materials ((b) and (c)).

of precursors used in the preparation of the final products are found to have a noticeable influence. The largest differences were observed for the percentage content of nitrogen and sulfur. Similar nitrogen content was found in samples with constant chitin content and variable lignin content (samples 1-7), which is to be expected since chitin has acetamide groups in its structure. In samples 9, 11, and 13 a decrease in nitrogen content is observed, which is a result of the diminishing fraction of chitin. A similar situation is found for sulfur content. In samples 1 to 7 the lignin content gradually decreases as is clearly confirmed by the decreasing percentage of sulfur in the products. In the other materials (samples 8-13) lignin content remains unchanged, while chitin content varies; thus the sulfur percentage content is similar. The changes in the percentage contents of carbon and hydrogen were comparably small. The highest carbon content was recorded for sample 1 (chitin : lignin ratio $1: 1$ ), and the smallest was recorded for sample 7 (chitin : lignin ratio $1: 0.05)$.

Elemental analysis enables estimation of the percentage elemental contribution in the precursors and in the final multifunctional chitin/lignin materials. The analysis provides proof of the different elemental compositions of the various samples and indirectly confirms the effectiveness of the preparation of chitin/lignin materials.

3.4. Electrokinetic Properties. Electrokinetic properties undoubtedly depend on the surface character of the examined materials. Thus in the next part of the research, the value of the zeta potential was determined as a function of $\mathrm{pH}$ (Figure 6), providing information about the electrokinetic properties of particles dispersed in aqueous systems.

Zeta potential was determined for the precursors (chitin and Kraft lignin) and for the obtained chitin/lignin materials 


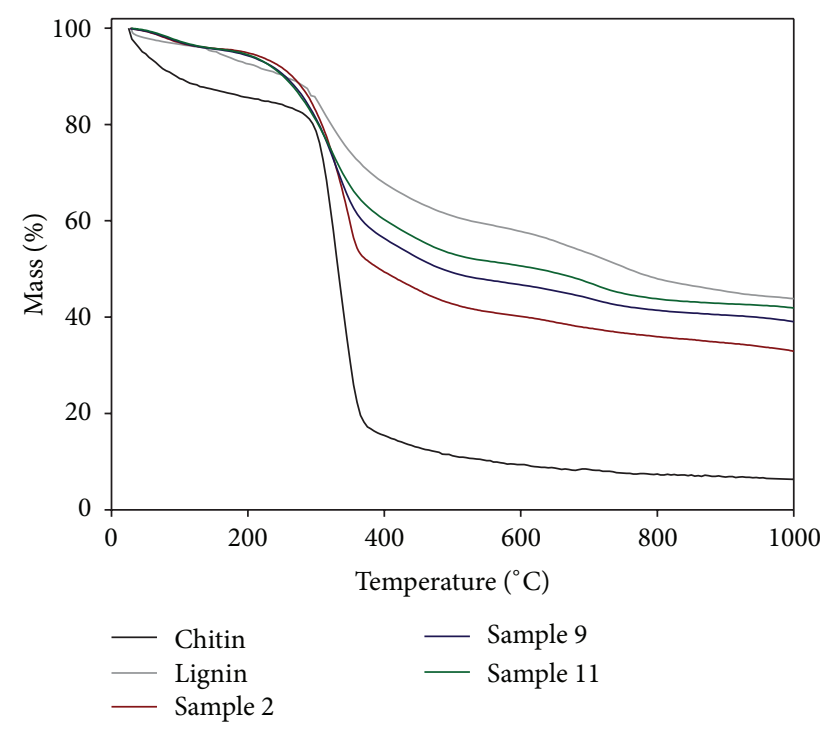

FIGURE 7: Thermogravimetric curves of precursors and resulting chitin/lignin materials.

with various weight fractions of the precursors. Measurements were carried out over a wide $\mathrm{pH}$ range (1-11) in $0.001 \mathrm{M} \mathrm{NaCl}$ solution. The stability of water dispersions was indirectly determined through the value of zeta potential. In addition, the effectiveness of the proposed multifunctional material synthesis was confirmed.

Chitin is obtained industrially via chemical isolation in three stages: demineralization, deproteinization, and depigmentation. The deproteinization stage is usually carried out using aqueous solution of $\mathrm{NaOH}$ or $\mathrm{KOH}$, which hydrolyses some of the acetamide bonds present in poly1,4-N-acetylglucosamine. Thus the process needs to be strictly controlled. Chitin is always a copolymer of $\mathrm{N}$ acetyloglucosamine and glucosamine mers, with a degree of deacetylation in the range 50-95\% [43]. Various functional groups present on the surface of chitin undergo protonation at solution $\mathrm{pH}$ values lower than $\mathrm{pH}_{\mathrm{IEP}}$. Amine groups ( $\mathrm{R}-$ $\left.\mathrm{NH}_{2}\right)$ undergo proteinization to $\left(\mathrm{RNH}_{3}\right)^{+}$. Consequently, in this solution, $\mathrm{pH}$ range, a formation of a positive surface charge, has been observed on the surface of chitin [44, 45]. The formation of the surface charge on chitin dispersed in an aqueous system can be expressed by the following reaction:

$$
\mathrm{R}-\mathrm{NH}_{2}+\mathrm{H}^{+} \Longleftrightarrow \mathrm{R}-\mathrm{NH}_{3}^{+}
$$

Surface $-\mathrm{NH}_{3}{ }^{+}$groups cause repulsive electrostatic forces between particles dispersed in aqueous systems. The $\mathrm{R}-\mathrm{NH}_{3}{ }^{+}$ group is weakly acidic, and its degree of proteinization is described by the value $p K_{a}$. According to calculations based on the value of $p K_{a}$, published in [45], surface amine groups are completely proteinized at a $\mathrm{pH}$ of 3.5 or lower and undergo complete dissociation at a $\mathrm{pH}$ of 7 . Between these two $\mathrm{pH}$ values, amine groups are only partly protonated [46]. From the results obtained for chitin's zeta potential, it was concluded that the isoelectric point (IEP) is equal to 3.49. At this point the colloidal system is the least stable. Over the analyzed $\mathrm{pH}$ range, chitin has zeta potential values ranging from 21 to $-38 \mathrm{mV}$. Chitin dispersed in aqueous systems exhibits good electrokinetic stability, particularly at alkaline $\mathrm{pH}$. Thus in these measurement conditions, repulsive forces prevail between dispersed chitin particles.

The electrokinetic curve of Kraft lignin, obtained as a result of zeta potential measurement, does not reach the isoelectric point; however, its shape suggests that it approaches IEP at a $\mathrm{pH}$ of around 1. Functional groups present on the surface of lignin have a significant influence on the obtained values of isoelectric point. Kraft lignin has a negative zeta potential over the entire $\mathrm{pH}$ range. The surface charge formed strongly depends on the degree of dissociation of such functional groups as $-\mathrm{OH},-\mathrm{COOH}$, and $-\mathrm{SH}$ present on the surface of the particles dispersed in the aqueous system [47]. From the work carried out under the present study and from available literature data, it can be concluded that a significant quantity of carboxyl and phenolic groups (and others) is present on the surface of Kraft lignin. The mechanism of surface charge formation has been discussed in detail in [48, 49]. The significant changes in zeta potential (and therefore in surface charge density) as a function of solution $\mathrm{pH}$ confirm unequivocally that in the analyzed dispersive system the potential-forming ions are $\mathrm{H}^{+}$and $\mathrm{OH}^{-}$. The electrokinetic analysis of Kraft lignin is in agreement with literature data available for the compound $[48,50]$.

Figures 6(b) and 6(c) show the electrokinetic curves of the obtained chitin/lignin materials with various weight fractions of the components. The suggested methodology of chitin/lignin system preparation makes it possible to obtain a final product with specified electrokinetic properties. The results of zeta potential measurements indirectly confirm the effectiveness of the proposed method of synthesis. Increasing the content of lignin in proportion to chitin causes a proportional decrease in the electrokinetic (zeta) potential values obtained. This is particularly noticeable for samples 9, 11, and 13 (Figure 6(c)), with chitin : lignin weight ratios of $0.5: 1,0.2: 1$, and $0.05: 1$, respectively. In turn, increasing the weight contribution of chitin in proportion to lignin caused a shift of the electrokinetic curve toward higher values of zeta potential. The most visible change in the surface charge was recorded for sample 7 (chitin : lignin ratio $1: 0.05$ ). The analyzed systems offer relatively good electrokinetic stability over a wide $\mathrm{pH}$ range. In these conditions particles will tend not to form agglomerates, due to the presence of repulsive forces between them, which is of great importance from the point of view of potential applications. The stability improves when the weight fraction of lignin relative to chitin increases.

3.5. Thermal Stability. Thermal stability measurements were performed for selected chitin/lignin materials. For comparison purposes, measurements were also made for the biopolymers. The obtained thermogravimetric curves show mass loss caused by the transformations that occur as the temperature increases. Figure 7 shows the TG curves obtained for the precursors and the results of the thermal analysis of selected final products.

The curves obtained for the initial biopolymers (Figure 7) show that chitin has a lower resistance to high temperature. 
The TG curve for chitin shows relatively significant mass loss of over $90 \%$. This occurs in two important stages. The first, at a temperature below $200^{\circ} \mathrm{C}$, involves desorption of water. The second, starting from $\sim 300^{\circ} \mathrm{C}$, involves considerable mass loss $(\sim 75 \%)$ associated with a one-step thermal degradation of the biopolymer [18]. Data published in the literature [51] confirm the results obtained in the present research.

In the case of lignin the thermogravimetric curve does not demonstrate such significant mass loss as with chitin (mass loss $\sim 60 \%$ of initial sample mass). The TG curve for lignin indicates three clear stages. The first, as in the case of chitin, is associated with loss of water. The second, the most important stage of high mass loss (about 35\%) in the temperature range $200-600^{\circ} \mathrm{C}$, is related to a complicated thermal decomposition of the compound, which includes bonds newly formed in cross-linking reactions. The third and last stage starts at a temperature of about $600^{\circ} \mathrm{C}$ and is associated with fragmentarization of the lignin compound and gradual thermal degradation. The data obtained are in agreement with the literature $[52,53]$.

Figure 7 shows the thermogravimetric curves of selected chitin/lignin products. Sample 2, containing the largest amount of chitin in proportion to lignin among the three analyzed products, displayed the lowest thermal stability (mass loss as high as $70 \%$ of the initial sample mass). Slightly better thermal properties were displayed by the other two materials, samples 9 and 11, which had similar mass loss values of $58 \%$ (sample 11) and 60\% (sample 9). The results at this stage of the experiment are in agreement with expectations. It is clear that the addition of lignin slightly improves the thermal stability of the resulting multifunctional chitin/lignin materials.

3.6. Porous Structure Analysis. In order to determine the porous structure parameters of the final products, analysis was carried out to determine the BET specific surface area, total volume, and mean size of pores. The results are shown in Figure 8. For comparison purposes, analysis of the precursors (chitin and lignin) was also carried out.

Values recorded for the BET specific surface area are relatively low, equal to $2.7 \mathrm{~m}^{2} / \mathrm{g}$ and $0.1 \mathrm{~m}^{2} / \mathrm{g}$ for chitin and lignin, respectively. Pore volume in chitin is significantly higher than in lignin. The mean size of chitin pores is $25.9 \mathrm{~nm}$, while that of lignin pores is smaller, at $12.1 \mathrm{~nm}$.

The lowest value of BET specific surface area among the analyzed samples was recorded for sample $13\left(1.2 \mathrm{~m}^{2} / \mathrm{g}\right)$, and the highest one was recorded for sample $7\left(3.0 \mathrm{~m}^{2} / \mathrm{g}\right)$. In the case of BET specific surface area, there are clear differences in the values obtained depending on the ratio of precursors used to prepare the final products. The values of total pore volume and pore size also clearly depend on the quantities of the precursors. With an increase in the chitin-to-lignin ratio (samples 1-7; Figure 8(c)), total pore volume increases up to $0.019 \mathrm{~cm}^{3} / \mathrm{g}$. Pore size also rises gradually, reaching a value of $25.1 \mathrm{~nm}$ for sample 7. Samples 8-13 (Figure 8(d)) show the reverse behavior. The values obtained for these samples show a gradual decrease in total pore volume and in pore size. Although the BET specific surface area is relatively low, the biomaterials should nonetheless be considered efficient and selective biosorbents, especially for harmful chemical substances, most importantly heavy metal ions. Very often, with the aim of improving lignin's adsorptive properties, surface activation is carried out in order to increase its surface area. One such process was suggested in [54]. The authors described a method of physical activation of lignin, consisting of carbonization of lignin in a nitrogen atmosphere in the first step and its activation using $\mathrm{CO}_{2}$ in the second. In this way a product was prepared with a surprisingly high BET surface area of $1613 \mathrm{~m}^{2} / \mathrm{g}$. It was reported that depending on the type of lignin used, activated carbon with various specific surface area parameters can be obtained [54].

Another method which may enable an increase in the specific surface area of biopolymers of this type is combination with an inorganic support offering excellent porous structure parameters, for instance, silica or magnesium silicate. The procedure significantly extends lignin's application as a selective biosorbent and results in an increase in capacity for heavy metal ion adsorption $[55,56]$.

Chitin, like lignin, has a great number of various functional groups in its structure; this means that in spite of the small BET surface area, these compounds cannot be excluded as biosorbents with good long-term promise.

The chitin/lignin material obtained can be identified with unique properties which enable it to be used as an effective sorbent of heavy metals. As part of the study, a test of the removal of cadmium(II) ions from aqueous solution was carried out using the chitin/lignin biosorbent, as well as native chitin and lignin. The influence of process duration (30$180 \mathrm{~min}$ ) on the effectiveness of adsorption of cadmium(II) ions $\left(30 \mathrm{mg} / \mathrm{dm}^{3}\right)$ was determined, as shown in Figure 9. It can be concluded that adsorption equilibrium was established after 60 minutes for both the chitin/lignin sorbent and the pure precursors. This can therefore be considered to be the most effective length of time for which the adsorption process should be maintained. Most importantly, the chitin/lignin sorbent proved to be the most effective. The efficiency of cadmium(II) ion removal reached values in the range 95.7-98.4\%, while for the lignin and chitin precursors, the values were only $65.9-71.8 \%$ and $78.0-84.8 \%$, respectively.

The results of the analyses indicate that chitin/lignin hybrids are excellent sorbents of heavy metal ions. It is expected that the investigated materials will be equally effective in the sorption of other heavy metals such as lead, mercury, chromium, and uranium. The results obtained provide a basis for realization of the adsorption process in real industrial waste systems.

3.7. Colorimetric Analysis. For the synthesized chitin/lignin products as well as for the initial precursors, colorimetric analysis was carried out using the CIE $L^{*} a^{*} b^{*}$ color system. The results are given in Table 2 .

Chitin has a light beige color, while lignin is a dark brown solid. The parameter $L^{*}$, determining brightness, is 85.47 for pure chitin and 41.26 for lignin. The parameters $a^{*}$ and $b^{*}$, reflecting the contribution of red and yellow in a sample's color, were as follows: for chitin $a^{*}=1.42$ and $b^{*}=14.43$; for pure lignin $a^{*}=10.16$ and $b^{*}=25.92$. Another important parameter in colorimetric analysis is the $d E$ variable, which 


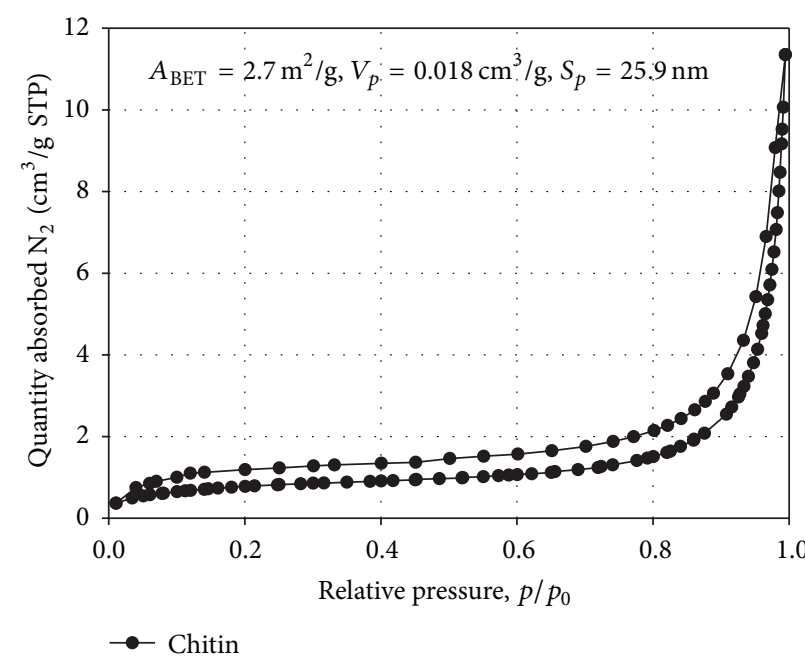

(a)

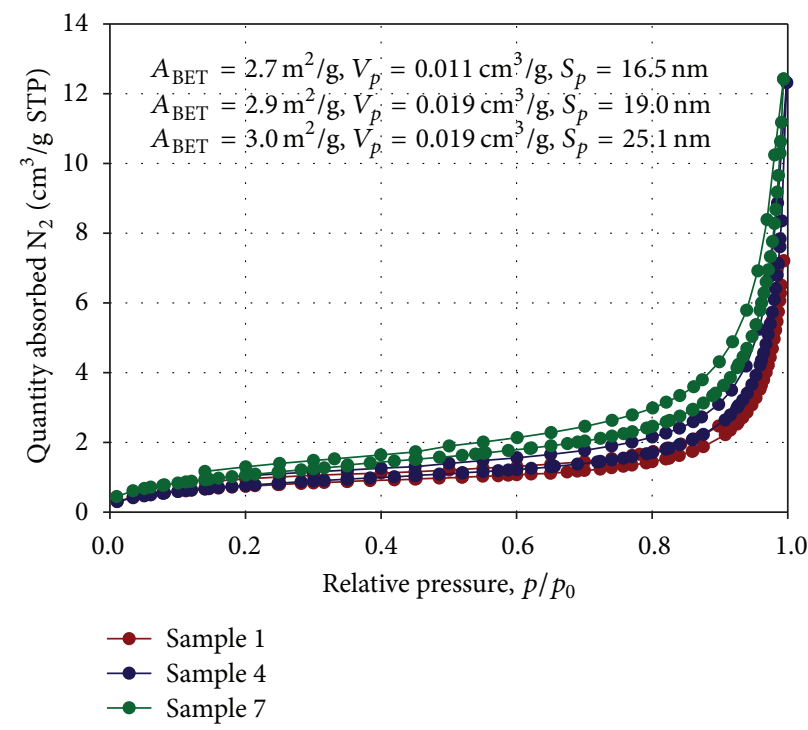

(c)

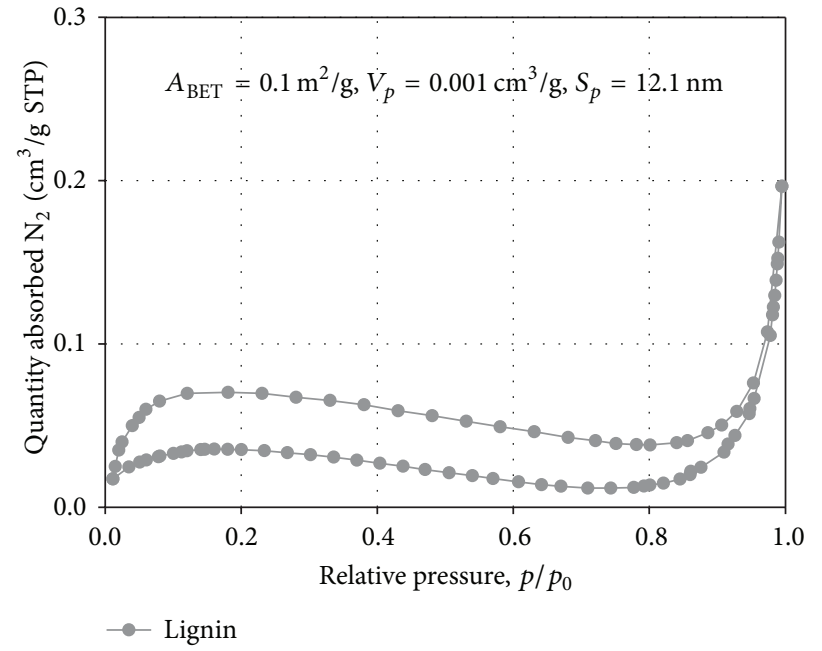

(b)

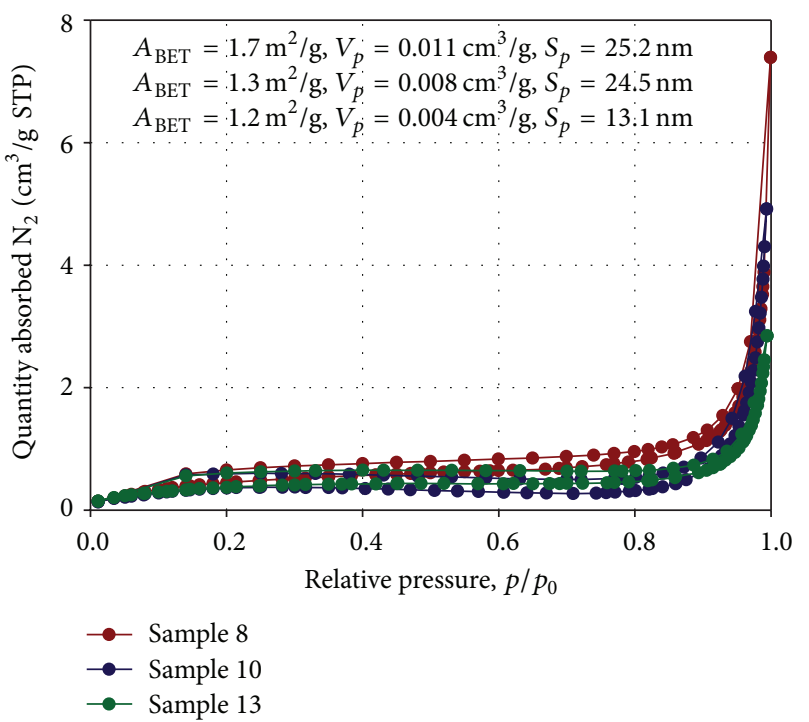

(d)

FIGURE 8: Nitrogen adsorption/desorption isotherms and adsorptive properties for chitin (a), lignin (b), and chitin/lignin materials ((c) and (d)).

determines total color change. For lignin its value is 58.24, and for chitin it is 14.41.

On analyzing the values of $L^{*}$, it is noticeable that for samples $1-7$, containing a constant amount of chitin and gradually diminishing amount of lignin, the value of the parameter systematically increases, reaching a value of 83.95 for sample 7. This is similar to the value obtained for pure chitin. For chitin/lignin samples from 8 to 13, where the chitin fraction decreases, the brightness parameter $L^{*}$ was found to decrease, down to a value of 50.98 for sample 13 (chitin : lignin ratio $0.25: 1$ ).

Comparing the values of parameters $a^{*}$ and $b^{*}$ for the final products $1-7$, a progressive decrease in red (parameter $\left.a^{*}\right)$ and yellow $\left(b^{*}\right)$ color is observed. For samples $8-13$, the values of these parameters systematically increase, reflecting the increasing color intensity of the obtained materials in which the content of chitin varies against a constant amount of lignin. The values of $d E$ confirm the correctness of the measurements. Initially its value decreases (samples 17), but in the later stage it increases (samples 8-13). The results obtained in this phase of the study are in agreement with expectations and confirm the appropriateness of the proposed method of synthesis. This means that the products may be utilized in various fields of industry in which color is a significant factor in production.

\section{Conclusions}

Advanced multifunctional materials have been obtained as a combination of natural polymers: chitin powder from crab shells and Kraft lignin. These precursors underwent a mechanical milling process with simultaneous mixing in 


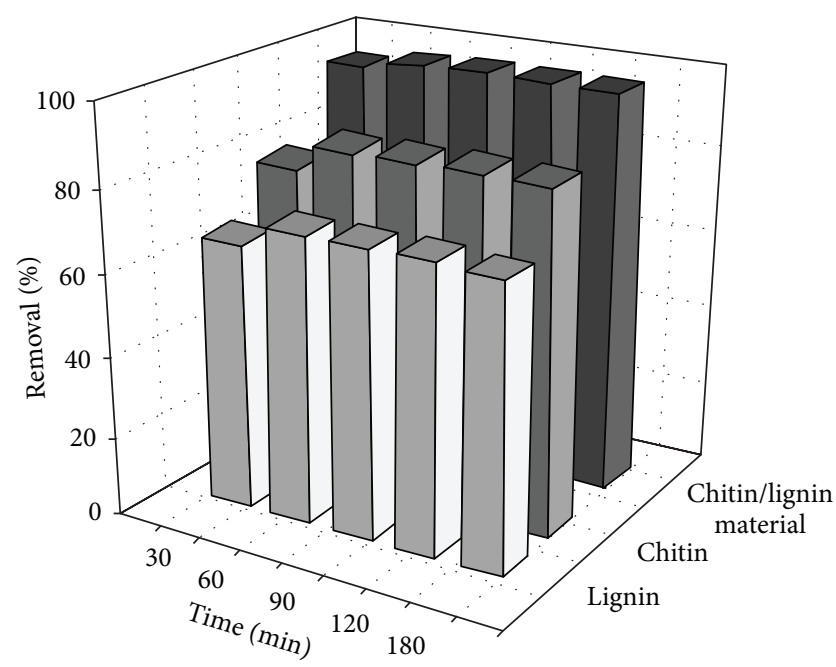

FIGURE 9: Effect of contact time on cadmium(II) removal efficiency by lignin, chitin, and chitin/lignin material.

TABLE 2: Colorimetric data of precursors (pure chitin and lignin) and chitin/lignin materials.

\begin{tabular}{lcccc}
\hline \multirow{2}{*}{ Sample number } & \multicolumn{4}{c}{ Colorimetric data } \\
& $L^{*}$ & $a^{*}$ & $b^{*}$ & $d E$ \\
\hline Pure chitin & 85.47 & 1.42 & 14.43 & 14.41 \\
Pure lignin & 41.26 & 10.16 & 25.92 & 58.24 \\
\hline 1 & 67.31 & 12.56 & 39.51 & 46.93 \\
2 & 67.37 & 11.74 & 38.69 & 45.26 \\
3 & 68.82 & 10.11 & 35.42 & 43.21 \\
4 & 71.08 & 8.46 & 32.92 & 38.64 \\
5 & 78.77 & 4.87 & 26.08 & 29.79 \\
6 & 81.29 & 3.63 & 22.32 & 24.92 \\
7 & 83.95 & 1.03 & 19.96 & 18.80 \\
8 & 60.66 & 12.13 & 38.21 & 50.08 \\
9 & 58.48 & 12.54 & 30.51 & 50.24 \\
10 & 58.02 & 13.17 & 34.73 & 50.86 \\
11 & 57.30 & 13.62 & 34.98 & 51.50 \\
12 & 57.09 & 14.04 & 36.80 & 52.42 \\
13 & 50.98 & 14.13 & 38.21 & 53.50 \\
\hline
\end{tabular}

a centrifugal ball mill. The final chitin/lignin products and the precursors were subjected to detailed physicochemical, dispersive-morphological, electrokinetic, thermal, and colorimetric analyses. The effectiveness of the preparation of chitin/lignin materials was confirmed by FT-IR spectra and elemental analysis. We suggest that the formation of chitin/lignin materials occurs by hydrogen bonding of the $-\mathrm{OH}$ and $=\mathrm{NH}$ groups of chitin with $-\mathrm{OH}$ groups from lignin. Increasing the quantity of lignin relative to chitin results in an improvement in the thermal properties of the analyzed systems, thus creating an opportunity to utilize the materials in biodegradable polymer fillers. The results of electrokinetic (zeta) potential measurements confirm the effectiveness of the preparation of the chitin/lignin materials. Moreover, their good electrokinetic stability gives reason to believe that they will find a wide spectrum of applications, including in medicine and pharmacy. Additionally, color measurements determined the most important colorimetric parameters, which may play a vital role in the production technology of new materials. The results of the analyses performed indicate that chitin/lignin hybrids act as excellent sorbents of heavy metal ions.

\section{Acknowledgments}

This work was supported by Poznan University of Technology research Grant no. 32-375/2013-DS, Mobilność Plus Program 920/MOB/2012/0, and DAAD Scholarship no. A/12/84687.

\section{References}

[1] H. L. Chum, Biomass (Organic Electrochemistry). An Introduction and Guide, H. Lund and H. M. Baizer, Eds., Marcel Dekker, New York, NY, USA, 1991.

[2] J. Ralph, K. Lundquist, G. Brunow et al., "Lignins: natural polymers from oxidative coupling of 4-hydroxyphenyl-propanoids," Phytochemistry Reviews, vol. 3, no. 1-2, pp. 29-60, 2004.

[3] S. R. Collinson and W. Thielemans, "The catalytic oxidation of biomass to new materials focusing on starch, cellulose and lignin," Coordination Chemistry Reviews, vol. 254, no. 15-16, pp. 1854-1870, 2010.

[4] M. Micic, K. Radotic, M. Jeremic, D. Djikanovic, and S. B. Kämmer, "Study of the lignin model compound supramolecular structure by combination of near-field scanning optical microscopy and atomic force microscopy," Colloids and Surfaces $B$, vol. 34, no. 1, pp. 33-40, 2004.

[5] L. A. Donaldson, "Lignification and lignin topochemistry-an ultrastructural view," Phytochemistry, vol. 57, no. 6, pp. 859-873, 2001.

[6] G. Milczarek, "Preparation and characterization of a lignin modified electrode," Electroanalysis, vol. 19, no. 13, pp. 1411-1414, 2007.

[7] G. Milczarek, "Lignosulfonate-modified electrodes: electrochemical properties and electrocatalysis of NADH oxidation," Langmuir, vol. 25, no. 17, pp. 10345-10353, 2009.

[8] G. Milczarek, "Kraft lignin as dispersing agent for carbon nanotubes," Journal of Electroanalytical Chemistry, vol. 638, no. 1, pp. 178-181, 2010.

[9] G. Milczarek and T. Rebis, "Synthesis and electroanalytical performance of a composite material based on poly(3,4ethylenedioxythiophene) doped with lignosulfonate," International Journal of Electrochemistry, vol. 2012, Article ID 130980, 7 pages, 2012.

[10] S. K. Srivastava, A. K. Singh, and A. Sharma, "Studies on the uptake of lead and zinc by lignin obtained from black liquor-a paper industry waste material," Environmental Technology, vol. 15, no. 4, pp. 353-361, 1994.

[11] D. Mohan, C. U. Pittman Jr., and P. H. Steele, "Single, binary and multi-component adsorption of copper and cadmium from aqueous solutions on Kraft lignin-a biosorbent," Journal of Colloid and Interface Science, vol. 297, no. 2, pp. 489-504, 2006.

[12] S. Babel and T. A. Kurniawan, "Low-cost adsorbents for heavy metals uptake from contaminated water: a review," Journal of Hazardous Materials, vol. 97, no. 1-3, pp. 219-243, 2003. 
[13] T. Dizhbite, G. Zakis, A. Kizima et al., "Lignin-a useful bioresource for the production of sorption-active materials," Bioresource Technology, vol. 67, no. 3, pp. 221-228, 1999.

[14] T. Kunanopparat, P. Menut, M.-H. Morel, and S. Guilbert, "Improving wheat gluten materials properties by Kraft lignin addition," Journal of Applied Polymer Science, vol. 125, no. 2, pp. 1391-1399, 2012.

[15] A. A. Morandim-Giannetti, J. A. M. Agnelli, B. Z. Lanças, R. Magnabosco, S. A. Casarin, and S. H. P. Bettini, "Lignin as additive in polypropylene/coir composites: thermal, mechanical and morphological properties," Carbohydrate Polymers, vol. 87, no. 4, pp. 2563-2568, 2012.

[16] J. N. Sheikh and K. H. Prabhu, "Chitin and chitosan biopolymers of the 21 st century," International Dyer, vol. 195, no. 7, pp. 20-25, 2010.

[17] F. Khoushab and M. Yamabhai, "Chitin research revisited," Marine Drugs, vol. 8, no. 7, pp. 1988-2012, 2010.

[18] Y. Wang, Y. Chang, L. Yu et al., "Crystalline structure and thermal property characterization of chitin from Antarctic krill (Euphausia superba)," Carbohydrate Polymers, vol. 92, no. 1, pp. 90-97, 2013.

[19] S. Ifuku, M. Nogi, K. Abe et al., "Simple preparation method of chitin nanofibers with a uniform width of 10-20 nm from prawn shell under neutral conditions," Carbohydrate Polymers, vol. 84, no. 2, pp. 762-764, 2011.

[20] W. Sajomsang and P. Gonil, "Preparation and characterization of $\alpha$-chitin from cicada sloughs," Materials Science and Engineering C, vol. 30, no. 3, pp. 357-363, 2010.

[21] E. Brunner, P. Richthammer, H. Ehrlich et al., "Chitin-based organic networks: an integral part of cell wall biosilica in the diatom thalassiosira pseudonana," Angewandte Chemie International Edition, vol. 48, no. 51, pp. 9724-9727, 2009.

[22] H. Ehrlich, M. Maldonado, K.-D. Spindler et al., "First evidence of chitin as a component of the skeletal fibers of marine sponges. Part I. Verongidae (Demospongia: Porifera)," Journal of Experimental Zoology B, vol. 308, no. 4, pp. 347-356, 2007.

[23] H. Ehrlich, M. Krautter, T. Hanke et al., "First evidence of the presence of chitin in skeletons of marine sponges. Part II. Glass sponges (Hexactinellida: Porifera)," Journal of Experimental Zoology B, vol. 308, no. 4, pp. 473-483, 2007.

[24] E. Brunner, H. Ehrlich, P. Schupp et al., "Chitin-based scaffolds are an integral part of the skeleton of the marine demosponge Ianthella basta," Journal of Structural Biology, vol. 168, no. 3, pp. 539-547, 2009.

[25] M. Rinaudo, "Chitin and chitosan: properties and applications," Progress in Polymer Science, vol. 31, no. 7, pp. 603-632, 2006.

[26] K. Kurita, "Chitin and chitosan: functional biopolymers from marine crustaceans," Marine Biotechnology, vol. 8, no. 3, pp. 203-226, 2006.

[27] R. Jayakumar, M. Prabaharan, P. T. Sudheesh Kumar, S. V. Nair, and H. Tamura, "Biomaterials based on chitin and chitosan in wound dressing applications," Biotechnology Advances, vol. 29, no. 3, pp. 322-337, 2011.

[28] R. Jayakumar, K. P. Chennazhi, S. Srinivasan, S. V. Nair, T. Furuike, and H. Tamura, "Chitin scaffolds in tissue engineering," International Journal of Molecular Sciences, vol. 12, no. 3, pp. 1876-1887, 2011.

[29] R. Jayakumar, A. Nair, N. S. Rejinold, S. Maya, and S. V. Nair, "Doxorubicin-loaded $\mathrm{pH}$-responsive chitin nanogels for drug delivery to cancer cells," Carbohydrate Polymers, vol. 87, no. 3 , pp. 2352-2356, 2012.
[30] K. T. Smitha, A. Anitha, T. Furuike, H. Tamura, S. V. Nair, and R. Jayakumar, "In vitro evaluation of paclitaxel loaded amorphous chitin nanoparticles for colon cancer drug delivery," Colloids and Surfaces B, vol. 104, pp. 245-253, 2013.

[31] H. Ehrlich, E. Steck, M. Ilan et al., "Three-dimensional chitin-based scaffolds from Verongida sponges (Demospongiae: Porifera). Part II: biomimetic potential and applications," International Journal of Biological Macromolecules, vol. 47, no. 2, pp. 141-145, 2010.

[32] P. X. Pinto, S. R. Al-Abed, and D. J. Reisman, "Biosorption of heavy metals from mining influenced water onto chitin products," Chemical Engineering Journal, vol. 166, no. 3, pp. 1002-1009, 2011.

[33] H. Tang, W. Zhou, and L. Zhang, "Adsorption isotherms and kinetics studies of malachite green on chitin hydrogels," Journal of Hazardous Materials, vol. 209-210, pp. 218-225, 2012.

[34] K. Kurita, "Controlled functionalization of the polysaccharide chitin," Progress in Polymer Science, vol. 26, no. 9, pp. 1921-1971, 2001.

[35] J. D. Kittle, C. Wang, C. Qian et al., "Ultrathin chitin films for nanocomposites and biosensors," Biomacromolecules, vol.13, no. 3, pp. 714-718, 2012.

[36] X. Wang and B. Xing, "Importance of structural makeup of biopolymers for organic contaminant sorption," Environmental Science and Technology, vol. 41, no. 10, pp. 3559-3565, 2007.

[37] S. L. James, C. J. Adams, C. Bolm et al., "Mechanochemistry: opportunities for new and cleaner synthesis," Chemical Society Reviews, vol. 41, no. 1, pp. 413-447, 2012.

[38] A. Tejado, C. Peña, J. Labidi, J. M. Echeverria, and I. Mondragon, "Physico-chemical characterization of lignins from different sources for use in phenol-formaldehyde resin synthesis," Bioresource Technology, vol. 98, no. 8, pp. 1655-1663, 2007.

[39] M. G. Alriols, A. García, R. Llano-ponte, and J. Labidi, "Combined organosolv and ultrafiltration lignocellulosic biorefinery process," Chemical Engineering Journal, vol. 157, no. 1, pp. 113120, 2010.

[40] G. Cárdenas, G. Cabrera, E. Taboada, and S. P. Miranda, "Chitin characterization by SEM, FTIR, XRD, and 13C cross polarization/mass angle spinning NMR," Journal of Applied Polymer Science, vol. 93, no. 4, pp. 1876-1885, 2004.

[41] R. L. Lavall, O. B. G. Assis, and S. P. Campana-Filho, “ $\beta$-Chitin from the pens of Loligo sp.: extraction and characterization," Bioresource Technology, vol. 98, no. 13, pp. 2465-2472, 2007.

[42] M.-K. Jang, B.-G. Kong, Y.-I. Jeong, C. H. Lee, and J.-W. Nah, "Physicochemical characterization of $\alpha$-chitin, $\beta$-chitin, and $\gamma$ chitin separated from natural resources," Journal of Polymer Science A, vol. 42, no. 14, pp. 3423-3432, 2004.

[43] R. J. Krupadam, P. Sridevi, and S. Sakunthala, "Removal of endocrine disrupting chemicals from contaminated industrial groundwater using chitin as a biosorbent," Journal of Chemical Technology and Biotechnology, vol. 86, no. 3, pp. 367-374, 2011.

[44] G. Annadurai, M. Chellapandian, and M. R. V. Krishnan, "Adsorption of reactive dye on chitin," Environmental Monitoring and Assessment, vol. 59, no. 1, pp. 111-119, 1999.

[45] L. Raymond, F. G. Morin, and R. H. Marchessault, "Degree of deacetylation of chitosan using conductometric titration and solid-state NMR," Carbohydrate Research, vol. 246, pp. 331-336, 1993.

[46] J. Li, J.-F. Revol, E. Naranjo, and R. H. Marchessault, "Effect of electrostatic interaction on phase separation behaviour of chitin crystallite suspensions," International Journal of Biological Macromolecules, vol. 18, no. 3, pp. 177-187, 1996. 
[47] W. Janusz and M. Matysek, "Coadsorption of Cd(II) and oxalate ions at the $\mathrm{TiO}_{2}$ /electrolyte solution interface," Journal of Colloid and Interface Science, vol. 296, no. 1, pp. 22-29, 2006.

[48] D. Dong, A. L. Fricke, B. M. Moudgil, and H. Johnson, "Electrokinetic study of kraft lignin," Tappi Journal, vol. 79, no. 7, pp. 191-197, 1996.

[49] Ł. Klapiszewski, M. Nowacka, G. Milczarek, and T. Jesionowski, "Physicochemical and electrokinetic properties of silica/lignin biocomposites," Carbohydrate Polymers, vol. 94, no. 1, pp. 345355, 2013.

[50] H. Harmita, K. G. Karthikeyan, and X. Pan, "Copper and cadmium sorption onto kraft and organosolv lignins," Bioresource Technology, vol. 100, no. 24, pp. 6183-6191, 2009.

[51] D. Stawski, S. Rabiej, L. Herczyńska, and Z. Draczyński, “Thermogravimetric analysis of chitins of different origin," Journal of Thermal Analysis and Calorimetry, vol. 93, no. 2, pp. 489-494, 2008.

[52] J. Rodríguez-Mirasol, T. Cordero, and J. J. Rodríguez, " $\mathrm{CO}_{2}{ }^{-}$ reactivity of eucalyptus kraft lignin chars," Carbon, vol. 31, no. 1, pp. 53-61, 1993.

[53] M. Kijima, T. Hirukawa, F. Hanawa, and T. Hata, "Thermal conversion of alkaline lignin and its structured derivatives to porous carbonized materials," Bioresource Technology, vol. 102, no. 10, pp. 6279-6285, 2011.

[54] S. Suhas, P. J. M. Carrott, and M. M. L. Ribeiro Carrott, "Lignin-from natural adsorbent to activated carbon: a review," Bioresource Technology, vol. 98, no. 12, pp. 2301-2312, 2007.

[55] G. Telysheva, T. Dizhbite, L. Jashina et al., "Synthesis of lignin-based inorganic/organic hybrid materials favorable for detoxification of ecosystem components," BioResources, vol. 4, no. 4, pp. 1276-1284, 2009.

[56] R. Saad and J. Hawari, "Grafting of lignin onto nanostructured silica SBA-15: preparation and characterization," Journal of Porous Materials, vol. 20, pp. 227-233, 2013. 

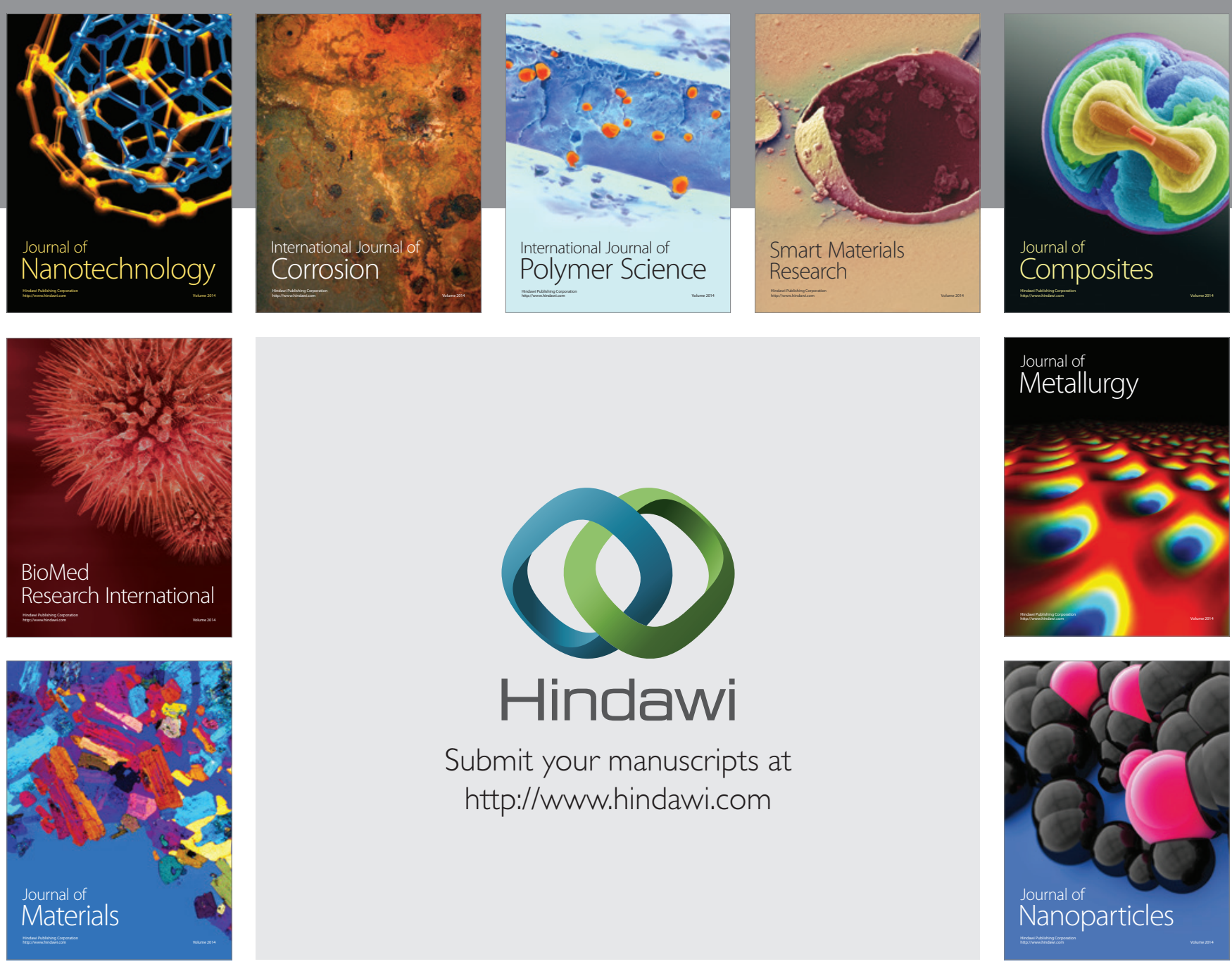

Submit your manuscripts at http://www.hindawi.com
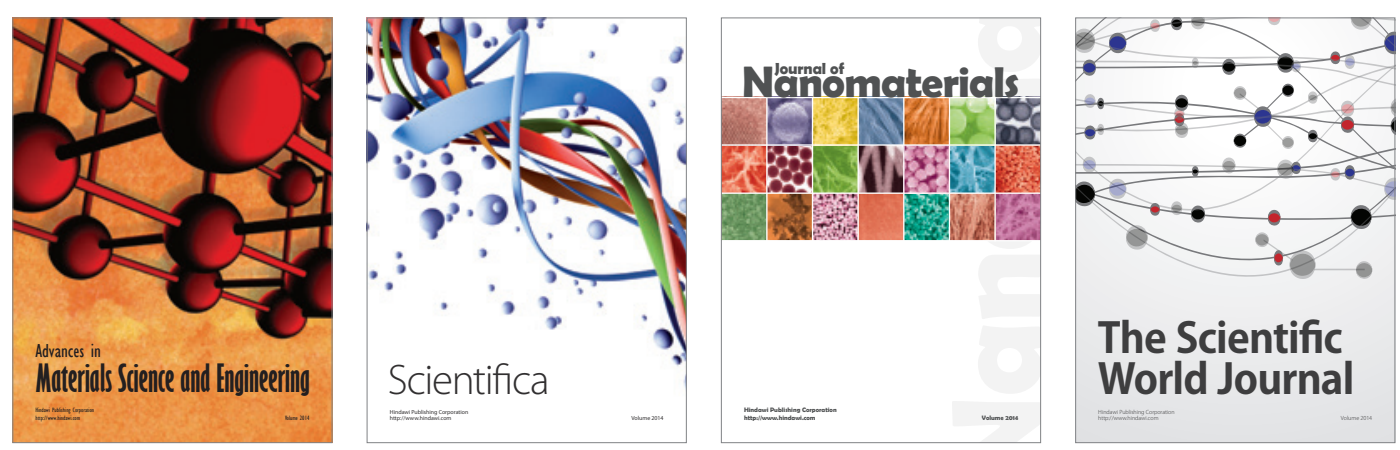

\section{The Scientific World Journal}
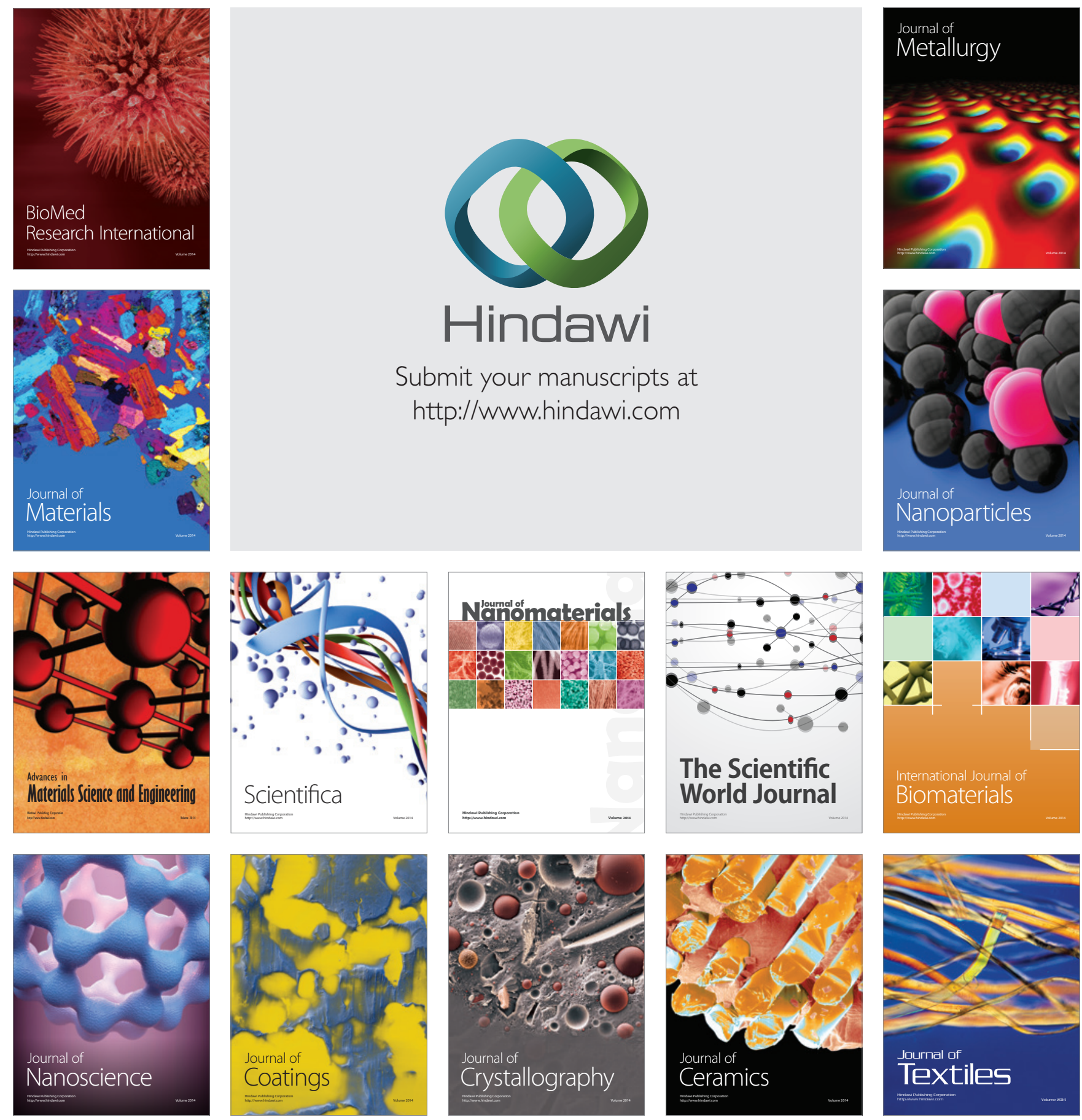